\title{
The critical interaction between valproate sodium and warfarin: case report and review
}

\author{
Chenguang Zhou' ${ }^{1}$ Yi Sui ${ }^{2 *}$, Weijin Zhao ${ }^{2}$, Chunyao Dong ${ }^{2}$, Li Ren², Pingmei Song ${ }^{3}$, Bing Xu ${ }^{2}$ and Xiaohong Sun ${ }^{4}$
}

\begin{abstract}
Background: Valproic acid (VPA) and warfarin are commonly prescribed for patients with epilepsy and concomitant atrial fibrillation (AF). When VPA and warfarin are prescribed together, clinically important interactions may occur. VPA may replace warfarin from the protein binding sites and result in an abnormally increased anticoagulation effect. This is commonly underrecognized.

Case presentation: In our case, we report a 78-year-old woman with a glioma who presented with status epilepticus. The patient was on warfarin to prevent cardiogenic embolism secondary to AF. Intravenous loading dose of VPA was administered, but international normalized ratio (INR) increased significantly to 8.26. Intravenous vitamin K1 was then given and the patient developed no overt bleeding during the hospitalization.

Conclusion: By reviewing the literature and discussing the critical interaction between valproate sodium and warfarin, we conclude that intravenous VPA and the co-administrated warfarin may develop critical but underrecognized complications due to effects on the function of hepatic enzymes and displacement of protein binding sites.
\end{abstract}

Keywords: Valproic acid, Warfarin, Interaction, International normalized ratio, Epilepsy

\section{Background}

Comorbidity associated with polypharmacy is increasingly common among older patients with epilepsy [1]. Antiepileptic drugs (AEDs) and co-administration of other medications may have clinically important implications due to their effects on the function of hepatic enzymes and displacement of protein binding sites [2]. The potential for an interaction between valproic acid (VPA) and warfarin has rarely been reported or discussed and in this study, we present an interaction between intravenous VPA and oral warfarin that resulted in a substantial increase in the international normalized ratio (INR).

\section{Case presentation}

A 78-year-old woman was admitted to the Department of Neurology on the third occurrence of generalized

\footnotetext{
* Correspondence: jakeyisui@icloud.com

${ }^{2}$ Department of Neurology, Shenyang First People's Hospital, Shenyang Brain Institute, Shenyang Medical College Affiliated Shenyang Brain Hospital,

Shenyang, China

Full list of author information is available at the end of the article
}

tonic clonic seizures (GTCS). A glioma had been diagnosed, and resection was performed 5 years previously. Following surgery, levetiracetam (LEV), $500 \mathrm{mg}$ once daily was prescribed but discontinued by the patient 1 month later. The past medical history was otherwise unremarkable, except for 14 years of warfarin use at $1.875 \mathrm{mg}$ per day prescribed for the secondary prevention of embolic events from paroxysmal atrial fibrillation (AF). The patient's INR had not been monitored for 6 months, but there was no overt bleeding.

On the day of admission, $10 \mathrm{mg}$ of diazepam was given intravenously to terminate a five-minute of GTCS while en route to a brain computerized tomography (CT) scan. The working diagnosis was status epilepticus (SE), and a loading dose of intravenous valproate sodium (1200 mg) was administrated to relieve the recurrent GTCS and frequent focal aware seizures. The patient remained physically well during interictal phase. Oral LEV of $500 \mathrm{mg}$ twice daily was prescribed when the patient had regained consciousness. Oral warfarin was not discontinued based on the initial INR of 2.02. The patient was also on $40 \mathrm{mg}$ oral isosorbide mononitrate sustained 
release tablets once daily and $12.5 \mathrm{mg}$ succinate metoprolol tablets twice daily as needed. The brain CT scan showed left frontal and parietal craniectomy and encephalomalacia at the left frontal lobe.

On the second day of admission, routine laboratory studies revealed otherwise unremarkable results, including PT $22.70 \mathrm{~s}$, PT\% 36, albumin $38.5 \mathrm{~g} / \mathrm{L}$, total protein $59.50 \mathrm{~g} / \mathrm{L}, \mathrm{TBIL} 41.6 \mu \mathrm{mol} / \mathrm{L}$, DBIL $7.10 \mu \mathrm{mol} / \mathrm{L}$, IBIL $34.50 \mu \mathrm{mol} / \mathrm{L}$, LDH $243 \mathrm{U} / \mathrm{L}$, and NT-pro BNP $1906 \mathrm{pg} /$ ml. ECG showed paroxysmal AF with a ventricular rate of $73 \mathrm{bpm}$. Carotid Doppler ultrasonography showed hypoechoic plaques on the anterior wall of the bifurcation of the right common carotid artery (Table 1).

The intravenous valproate sodium was discontinued at $44 \mathrm{~h}$ after admission, and a total dosage of which was approximately $2200 \mathrm{mg}$. Although seizure ceased from the start of VPA infusion, $18 \mathrm{~h}$ of video-monitoring electroencephalogram (EEG) commenced $5 \mathrm{~h}$ later. This demonstrated global interictal $\theta$ waves $(4-7 \mathrm{~Hz}$ ), but without epileptiform discharges.

On the 3rd hospital day, the patient developed a renal dysfunction based on the results of BUN $13.74 \mathrm{mmol} / \mathrm{l}$ and serum creatinine $126 \mu \mathrm{mol} / \mathrm{l}$, which was attributed to insufficient fluid intake. Coincidentally, the INR was found to be 8.26 , and INR $9 \mathrm{~h}$ later was 5.52. Oral warfarin was paused but was mistakenly given again $6 \mathrm{~h}$ later by a caregiver. A third INR revealed an almost identical value of 5.32. Following consultation with a hematologist, $5 \mathrm{mg}$ of vitamin K1 was given intravenously and the INR $8 \mathrm{~h}$ later was 2.16. The patient remained asymptomatic and without evident bleeding. A repeat brain CT scan revealed no intracranial hemorrhage. The renal dysfunction was corrected on the 4th day. The repeat BUN and serum creatinine were $9.33 \mathrm{mmol} / \mathrm{l}$ and $79 \mu \mathrm{mol} / \mathrm{l}$, respectively. Based on the observation of an INR of 2.16, warfarin was carefully restarted with a dose of $1.25 \mathrm{mg}$ and titrated back to $1.875 \mathrm{mg}$ with steady

Table 1 Abnormal laboratory results on Day 2

\begin{tabular}{ll}
\hline Items & Results or descriptions \\
\hline Albumin & $38.5 \mathrm{~g} / \mathrm{L}$ \\
Total protein & $59.50 \mathrm{~g} / \mathrm{L}$ \\
TBIL & $41.6 \mu \mathrm{mol} / \mathrm{L}$ \\
DBIL & $7.10 \mu \mathrm{mol} / \mathrm{L}$ \\
IBIL & $34.50 \mu \mathrm{mol} / \mathrm{L}$ \\
LDH & $243 \mathrm{U} / \mathrm{L}$ \\
NT-pro BNP & $1906 \mathrm{pg} / \mathrm{ml}$ \\
ECG & paroxysmal AF with a ventricular rate of 73 bpm \\
Carotid Doppler & hypoechoic plaques on the anterior wall of the \\
ultrasonography & bifurcation of the right common carotid artery \\
\hline
\end{tabular}

monitoring of the INR to ensure a value between 2 and 3 (Table 2).

\section{Discussion and conclusion}

Prior to this case, we had noted that warfarin could interact with many AEDs, such as carbamazepine, phenytoin, and others. The theoretical drug-drug interaction between warfarin and VPA has been hypothesized and previously proposed [3, 4], but the real-world interaction between these two drugs has been scarcely discussed. Previously, Yoon et al. reported a similar case of an unexpected and substantial increase of INR due to the co-administration of valproate and warfarin [5]. Interestingly, both Yoon et al. and our study share the similarity that both of the patients were coincidently given LEV, either orally or intravenously. The mechanism of action of LEV appears to involve neuronal binding to synaptic vesicle protein $2 \mathrm{~A}$, inhibiting calcium release from intraneuronal vesicles and $\mathrm{N}$-type calcium channels [6]. The metabolism of LEV is mostly independent of the CYP enzyme system, and LEV is neither an inducer nor inhibitor of these enzymes [6, 7]. In addition, LEV at a dose of $2000 \mathrm{mg} / \mathrm{d}$ does not affect the pharmacokinetics of warfarin [8]. In short, an interaction between LEV and warfarin seems unlikely, although we cannot entirely exclude any synergistic effects of LEV and VPA on warfarin or the potentiation of LEV regarding the interaction between VPA and warfarin. Except for VPA and warfarin, the only medications administered to the patient during this admission were intravenous diazepam, oral levetiracetam, isosorbide mononitrate sustained release tablets and succinate metoprolol tablets. No clinical-relevant interactions between warfarin and these medications have been documented or identified in the literature or drug interaction database. Importantly, no other medications, in particular vasoactive drugs, proton pump inhibitors or antibiotics were administered immediately before or during hospitalization.

Warfarin is composed of two racemic active forms, R-enantiomers and S-enantiomers, serum depletion and metabolism of which largely depends on hepatic enzymes $[9,10]$. R-isomers are 2-5 times less potent than their S-isomer counterparts [11]. More specifically, inactivation and metabolism of R-enantiomers occur via CYP1A2 and CYP3A4, while that of S-enantiomers occur via CYP2C9 [12]. Inducers or inhibitors of these enzymes may influence the metabolism of warfarin and, thereafter, its blood concentration. For instance, amiodarone is a CYP2C9 inhibitor that can enhance warfarin's anticoagulation effect [13], and carbamazepine is an CYP2C9 inducer that reduces its anticoagulant effect [14]. Likewise, VPA is an inhibitor of CYP2C9, uridine diphosphate glucuronosyltransferase, and epoxide hydrolase [15]. Presumably, activity of the CYP2C9 enzyme is 
Table 2 Medications and changes of key laboratory abnormalities

\begin{tabular}{|c|c|c|c|c|c|c|c|}
\hline & Premorbidity & Day 1 & Day 2 & Day 3 & Day 4 & Day 5 & Discharge \\
\hline Warfarin PO & $1.875 \mathrm{mg}$ QD & $1.875 \mathrm{mg}$ QD & $1.875 \mathrm{mg}$ QD & paused & $1.25 \mathrm{mg} \mathrm{QD}$ & $1.875 \mathrm{mg}$ QD & $1.875 \mathrm{mg}$ QD \\
\hline Diazepam IV & & $10 \mathrm{mg}$ & & & & & \\
\hline LEV PO & $500 \mathrm{mg}$ QD & $500 \mathrm{mg} \mathrm{BID}$ & $500 \mathrm{mg}$ BID & $500 \mathrm{mg} \mathrm{BID}$ & $500 \mathrm{mg}$ BID & $500 \mathrm{mg} \mathrm{BID}$ & 500 mg BID \\
\hline $\begin{array}{l}\text { Valproate } \\
\text { sodium IV }\end{array}$ & & \multicolumn{6}{|c|}{$\begin{array}{l}1200 \mathrm{mg} \\
\text { Discontinuation at accumulated dose of } 2200 \mathrm{mg}\end{array}$} \\
\hline Vitamin K1 IV & & & & $5 \mathrm{mg}$ & & & \\
\hline $\begin{array}{l}\text { Other } \\
\text { medications }\end{array}$ & \multicolumn{7}{|c|}{ isosorbide mononitrate sustained release tablets 40 mg PO QD, succinate metoprolol tablets 12.5 mg PO BID } \\
\hline INR (time) & & $2.02(10: 51)$ & $2.04(09: 30)$ & $\begin{array}{l}8.26(10: 56) \\
5.52(16: 11) \\
5.32(22: 41)\end{array}$ & $2.16(06: 18)$ & $2.07(09: 34)$ & $2.43(10: 01)$ \\
\hline PT (seconds) & & 22.50 & 22.70 & $\begin{array}{l}86.90 \\
63.00 \\
60.80\end{array}$ & 24.20 & 23.30 & 27.50 \\
\hline Creatinine $(\mu \mathrm{mol} / \mathrm{l})$ & & 75 & & 126 & 79 & 64 & 58 \\
\hline Albumin (g/L) & & & 38.50 & & & & 31.60 \\
\hline
\end{tabular}

LEV levetiracetam, IV intravenous, INR international normalized ratio, PT prothrombin time, $Q D$ once daily, BID twice daily, $P O$ by mouth

inhibited by VPA, and as a result, S-warfarin inactivation is lessened and its serum concentration is accordingly increased. However, why intravenous rather than oral administration of valproate has this effect remains elusive.

This influence of CYP inhibitors on the metabolism of warfarin usually initiates within $24 \mathrm{~h}$ after addition of the inhibitor, but the time to maximal affect depends on the time at which both interacting drugs reach their steady state [15]. Although warfarin has an average half-life of $40 \mathrm{~h}$ [9], based on our observation in this case, the interaction between valproate and warfarin may be transient, since the INR value decreased dramatically from 8.26 to 5.52 within $8 \mathrm{~h}$ without any intervention.

Given that intravenous VPA is more than $85 \%$ protein bound and oral warfarin is $95 \%$ protein bound at therapeutic concentrations [16, 17], displacement of warfarin from its protein binding sites and subsequent redistribution may also account for their interaction $[15,18,19]$. In this regard, Rolan PE et al. proposed that intravenous agents with high protein-binding rates, high hepatic extraction ratios, and narrow therapeutic windows may exhibit clinically significant interactions by way of competitive displacement [19].

Impaired renal function, in particular chronic kidney disease, is associated with increased bleeding risk in older adults using warfarin [20-22]. Although specific mechanisms are not well understood, animal studies suggest that downregulation of cytochrome enzymes may alter the pharmacokinetics of warfarin in the presence of renal dysfunction [23, 24]. Specifically for this patient, hypoalbuminemia may also increase levels of unbound warfarin, INR and bleeding risk [25, 26]. According to a cross-sectional analysis, Limdi NA and colleagues suggested a $9.5 \%$ and $19 \%$ lower dose of warfarin, respectively for patients with the estimated glomerular filtration rate (eGFR) of $30-59 \mathrm{~mL} / \mathrm{min} / 1.73 \mathrm{~m}^{2}$ and eGFR $<30 \mathrm{~mL} /$ $\min / 1.73 \mathrm{~m}^{2}$ [27].

Therapeutic drug monitoring can be particularly helpful in AED-treated elderly patients with conditions such as renal/liver disease or low albumin concentrations, trading off between seizure control and adverse effects [28-32]. Specifically for this patient, detection of high serum concentrations of VPA may account for, at least partly, the abovementioned competitive displacement of protein-binding sites or inhibition of CYP2C9 enzyme with warfarin. However, because VPA is a highly and saturable protein binding drug with $30 \%$ of free fraction at a concentration of $150 \mathrm{mg} / \mathrm{L}$ [30, 33], measurement of protein unbound VPA instead may reflect the true levels of its free components. In fact, measurement of unbound concentrations for highly protein bound AEDs such as VPA and phenytoin (i.e., $>90 \%$ ) has been increasingly recommended [30-32, 34]. Unfortunately, neither total nor unbound concentration of VPA was examined in this patient due to guardian's disconsent.

VPA is effective for treating focal and generalized epilepsies with well-established tolerability. An injectable formulation has been available since 1993, and the most commonly effective doses for treating SE vary between 15 and $45 \mathrm{mg} / \mathrm{kg}$ in bolus ( 6 or $10 \mathrm{mg} / \mathrm{kg} / \mathrm{min}$ ) followed by $1-3 \mathrm{mg} / \mathrm{kg} / \mathrm{h}$ infiltration [35-39]. The most reported adverse effects of intravenous VPA is dizziness, thrombocytopenia, and hypotension [38].

Comorbidity has been increasingly noted among older individuals newly diagnosed with epilepsy. Of 259 patients on oral VPA in a registry, $29 \%$ had AF, $36 \%$ were 
receiving warfarin for various reasons [1] and importantly, 19\% of enzyme-inducing AED users reported concomitant usage of warfarin. Besides the INR enhancement we described in this case, VPA may also cause thrombocytopenia and further impair platelet aggregation [40]. Therefore, when physicians decide to start VPA, particularly intravenously, in patients who are simultaneously on warfarin, caution should be taken and the INR should be closely monitored. Optimally, from our point of view, concurrent use of warfarin and intravenous VPA should be avoided, either by replacing warfarin with new oral anticoagulants (NOACs) or substituting intravenous VPA with benzodiazepines, such as lorazepam or diazepam. The efficacy of intravenous diazepam for controlling generalized convulsive status epilepticus is not different than that of VPA, despite its potentiation in regard to respiratory depression or hypotension $[35,41]$.

In conclusion, we reported an AF patient on oral warfarin presenting with SE and the intravenous VPA was used to control the epileptic seizures. We observed a significant INR level elevation in this patient. We conclude that intravenous VPA and the co-administrated warfarin may have clinically important implications due to effects on the function of hepatic enzymes and displacement of protein binding sites.

\section{Abbreviations}

AEDs: Antiepileptic drugs; AF: Atrial fibrillation; BID: Twice daily; BNP: Brain natriuretic peptide; CT: Computerized tomography; CYP: Cytochrome P450; DBIL: Direct bilirubin; EEG: Electroencephalogram; eGFR: Estimated glomerular filtration rate; GTCS: Generalized tonic clonic seizures; IBIL: Indirect bilirubin; INR: International normalized ratio; LDH: Lactate dehydrogenase; LEV: Levetiracetam; NOACs: New oral anticoagulants; PO: By mouth; PT: Prothrombin time; QD: Once daily; SE: Status epilepticus; TBIL: Total bilirubin; VPA: Valproic acid

\section{Acknowledgements}

We thank Dr. Morgan Tucker and Professor Malcolm Horne for English editing and constructive suggestions.

\section{Funding}

This work was supported by Liaoning Provincial Natural Science Foundation (ID 2015020547), China Postdoctoral Science Foundation (ID 2015 M581375) and National Natural Science Foundation of China (ID81371395) to Dr. Yi Sui. There was no role of the funding bodies in the design of the study and collection, analysis and interpretation of data as well as in writing the manuscript.

\section{Availability of data and materials}

The datasets supporting the conclusions of this article are included within the article and its additional files.

\section{Authors' contributions}

Study conception and design: YS, CZ, WZ, BX and CD. Acquisition, analysis, or interpretation of data: YS, WZ, CD, LR, PS and BX. Manuscript preparation: YS, CZ, WZ, and CD. Critical revision of the manuscript for important intellectual content: YS, BX and XS. Study supervision: YS. All authors have read and approved the final version of the manuscript.

\section{Ethics approval and consent to participate}

This study was approved by the ethical review committee of Shenyang First People's Hospital, Shenyang Brain Institute, Shenyang Medical College Affiliated Shenyang Brain Hospital.

\section{Consent for publication}

Written consent to publish all the personal and medical details included in the case report, as well as the accompanying laboratory data was obtained by the patient.

\section{Competing interests}

The authors declare that they have no competing interests.

\section{Publisher's Note}

Springer Nature remains neutral with regard to jurisdictional claims in published maps and institutional affiliations.

\section{Author details}

${ }^{1}$ Department of Neurology, The Fifth Affiliated Hospital of Zhengzhou University, Zhengzhou, China. ${ }^{2}$ Department of Neurology, Shenyang First People's Hospital, Shenyang Brain Institute, Shenyang Medical College Affiliated Shenyang Brain Hospital, Shenyang, China. ${ }^{3}$ Department of Diagnostic Sonography, Shenyang First People's Hospital, Shenyang Brain Institute, Shenyang Medical College Affiliated Shenyang Brain Hospital, Shenyang, China. ${ }^{4}$ Department of Neurology, the Fourth Affiliated Hospital, China Medical University, Shenyang, China.

Received: 4 July 2018 Accepted: 26 September 2018

Published online: 01 October 2018

\section{References}

1. Bruun E, Virta $\sqcup$, Kalviainen R, Keranen T. Co-morbidity and clinically significant interactions between antiepileptic drugs and other drugs in elderly patients with newly diagnosed epilepsy. Epilepsy Behav. 2017;73:71-6.

2. Patsalos PN, Perucca E. Clinically important drug interactions in epilepsy: general features and interactions between antiepileptic drugs. Lancet Neurol. 2003;2(6):347-56.

3. Guthrie SK, Stoysich AM, Bader G, Hilleman DE. Hypothesized interaction between valproic acid and warfarin. J Clin Psychopharmacol. 1995;15(2):138-9.

4. Stephen LJ. Drug treatment of epilepsy in elderly people: focus on valproic acid. Drugs Aging. 2003;20(2):141-52.

5. Yoon HW, Giraldo EA, Wijdicks EF. Valproic acid and warfarin: an underrecognized drug interaction. Neurocrit Care. 2011;15(1):182-5.

6. Lyseng-Williamson KA. Levetiracetam: a review of its use in epilepsy. Drugs. 2011;71(4):489-514.

7. Patsalos PN. Clinical pharmacokinetics of levetiracetam. Clin Pharmacokinet. 2004;43(11):707-24.

8. Ragueneau-Majlessi I, Levy $\mathrm{RH}$, Meyerhoff C. Lack of effect of repeated administration of levetiracetam on the pharmacodynamic and pharmacokinetic profiles of warfarin. Epilepsy Res. 2001;47(1-2):55-63.

9. Mega JL, Simon T. Pharmacology of antithrombotic drugs: an assessment of oral antiplatelet and anticoagulant treatments. Lancet. 2015;386(9990):281-91.

10. Bachawati M. Anticoagulation and psychotropic medications. Curr Psychiatry Rep. 2010;12(3):265-71.

11. Hirsh J, Fuster V, Ansell J, Halperin JL, American Heart A, American College of Cardiology F. American Heart Association/American College of Cardiology Foundation quide to warfarin therapy. Circulation. 2003;107(12):1692-711.

12. Kaminsky LS, Zhang ZY. Human P450 metabolism of warfarin. Pharmacol Ther. 1997;73(1):67-74.

13. Heimark LD, Wienkers L, Kunze K, Gibaldi M, Eddy AC, Trager WF, et al. The mechanism of the interaction between amiodarone and warfarin in humans. Clin Pharmacol Ther. 1992;51(4):398-407.

14. Freedman MD, Olatidoye AG. Clinically significant drug interactions with the oral anticoagulants. Drug Saf. 1994;10(5):381-94.

15. Anderson GD. A mechanistic approach to antiepileptic drug interactions Ann Pharmacother. 1998:32(5):554-63.

16. Cloyd JC, Dutta S, Cao G, Walch JK, Collins SD, Granneman GR. Valproate unbound fraction and distribution volume following rapid infusions in patients with epilepsy. Epilepsy Res. 2003;53(1-2):19-27. 
17. Nadkarni A, Oldham MA, Howard M, Berenbaum I. Drug-drug interactions between warfarin and psychotropics: updated review of the literature. Pharmacotherapy. 2012;32(10):932-42.

18. Sellers EM, Koch-Weser J. Kinetics and clinical importance of displacement of warfarin from albumin by acidic drugs. Ann N Y Acad Sci. 1971;179:213-25.

19. Rolan PE. Plasma protein binding displacement interactions - why are they still regarded as clinically important? Br J Clin Pharmacol. 1994;37(2):125-8.

20. Jun M, James MT, Manns BJ, Quinn RR, Ravani P, Tonelli M, et al. The association between kidney function and major bleeding in older adults with atrial fibrillation starting warfarin treatment: population based observational study. BMJ. 2015;350:h246.

21. Dahal K, Kunwar S, Rijal J, Schulman P, Lee J. Stroke, major bleeding, and mortality outcomes in warfarin users with atrial fibrillation and chronic kidney disease: a meta-analysis of observational studies. Chest. 2016; 149(4):951-9.

22. Olesen JB, Lip GY, Kamper AL, Hommel K, Kober L, Lane DA, et al. Stroke and bleeding in atrial fibrillation with chronic kidney disease. N Engl J Med. 2012;367(7):625-35.

23. Nolin TD. Altered nonrenal drug clearance in ESRD. Curr Opin Nephrol Hypertens. 2008;17(6):555-9.

24. Dreisbach AW, Lertora JJ. The effect of chronic renal failure on drug metabolism and transport. Expert Opin Drug Metab Toxicol. 2008;4(8): 1065-74.

25. Ganeval D, Fischer AM, Barre J, Pertuiset N, Dautzenberg MD, Jungers $P$, et al. Pharmacokinetics of warfarin in the nephrotic syndrome and effect on vitamin K-dependent clotting factors. Clin Nephrol. 1986;25(2): 75-80.

26. Abdelhafiz AH, Myint MP, Tayek JA, Wheeldon NM. Anemia hypoalbuminemia, and renal impairment as predictors of bleeding complications in patients receiving anticoagulation therapy for nonvalvular atrial fibrillation: a secondary analysis. Clin Ther. 2009;31(7):1534-9.

27. Limdi NA, Limdi MA, Cavallari L, Anderson AM, Crowley MR, Baird MF, et al. Warfarin dosing in patients with impaired kidney function. Am J Kidney Dis. 2010;56(5):823-31.

28. Wallenburg E, Klok B, de Jong K, de Maat M, van Erp N, StalpersKonijnenburg S, et al. Monitoring protein-unbound Valproic acid serum concentrations in clinical practice. Ther Drug Monit. 2017;39(3):269-72.

29. Patsalos PN, Spencer EP, Berry DJ. Therapeutic drug monitoring of antiepileptic drugs in epilepsy: a 2018 update. Ther Drug Monit. 2018;40: 526-48.

30. Patsalos PN, Zugman M, Lake C, James A, Ratnaraj N, Sander JW. Serum protein binding of 25 antiepileptic drugs in a routine clinical setting: a comparison of free non-protein-bound concentrations. Epilepsia. 2017;58(7): 1234-43.

31. Farrokh S, Tahsili-Fahadan P, Ritzl EK, Lewin JJ 3rd, Mirski MA. Antiepileptic drugs in critically ill patients. Crit Care. 2018;22(1):153.

32. Landmark CJ, Johannessen SI, Tomson T. Dosing strategies for antiepileptic drugs: from a standard dose for all to individualised treatment by implementation of therapeutic drug monitoring. Epileptic Dis. 2016;18(4): 367-83.

33. Patsalos PN, Berry DJ, Bourgeois BF, Cloyd JC, Glauser TA, Johannessen SI, et al. Antiepileptic drugs - best practice guidelines for therapeutic drug monitoring: a position paper by the subcommission on therapeutic drug monitoring, ILAE commission on therapeutic strategies. Epilepsia. 2008;49(7): 1239-76.

34. Stepanova D, Beran RG. The benefits of antiepileptic drug (AED) blood level monitoring to complement clinical management of people with epilepsy. Epilepsy Behav. 2015;42:7-9.

35. Prasad M, Krishnan PR, Sequeira R, Al-Roomi K. Anticonvulsant therapy for status epilepticus. Cochrane Database Syst Rev. 2014;(9):Cd003723.

36. Mundlamuri RC, Sinha S, Subbakrishna DK, Prathyusha PV, Nagappa M, Bindu PS, et al. Management of generalised convulsive status epilepticus (SE): a prospective randomised controlled study of combined treatment with intravenous lorazepam with either phenytoin, sodium valproate or levetiracetam—pilot study. Epilepsy Res. 2015;114:52-8.

37. Dutta S, Faught E, Limdi NA. Valproate protein binding following rapid intravenous administration of high doses of valproic acid in patients with epilepsy. J Clin Pharm Ther. 2007;32(4):365-71.

38. Trinka E, Hofler J, Zerbs A, Brigo F. Efficacy and safety of intravenous valproate for status epilepticus: a systematic review. CNS Drugs. 2014; 28(7):623-39.
39. Visudtibhan A, Bhudhisawadi K, Vaewpanich J, Chulavatnatol S, Kaojareon S. Pharmacokinetics and clinical application of intravenous valproate in Thai epileptic children. Brain Dev. 2011;33(3):189-94.

40. Nasreddine W, Beydoun A. Valproate-induced thrombocytopenia: a prospective monotherapy study. Epilepsia. 2008;49(3):438-45.

41. Chen WB, Gao R, Su YY, Zhao JW, Zhang YZ, Wang L, et al. Valproate versus diazepam for generalized convulsive status epilepticus: a pilot study. Eur J Neurol. 2011;18(12):1391-6.

\section{Ready to submit your research? Choose BMC and benefit from:}

- fast, convenient online submission

- thorough peer review by experienced researchers in your field

- rapid publication on acceptance

- support for research data, including large and complex data types

- gold Open Access which fosters wider collaboration and increased citations

- maximum visibility for your research: over $100 \mathrm{M}$ website views per year

At BMC, research is always in progress.

Learn more biomedcentral.com/submissions 